\title{
Application of Multielectrode Mapping \\ to Assess the Effect of Mechanical Right Atrium Distension on the Work of the Isolated Rat Heart
}

\author{
DOI: $10.17691 / \mathrm{stm} 2018.10 .4 .13$
}

Received April 24, 2018

E.E. Kharkovskaia, Leading Engineer, Laboratory of Electrophysiology and Living Systems Modeling, Institute of Information Technologies, Mathematics, and Mechanics ${ }^{1}$; Tutor, Department of Neurotechnologies, Institute of Biology and Biomedicine';

A.A. Kulikova, Student, Department of System Dynamics and Control Theory, Institute of Information Technologies, Mathematics, and Mechanics ${ }^{1}$;

R.D. Kataev, Student, Department of System Dynamics and Control Theory, Institute of Information Technologies, Mathematics, and Mechanics ${ }^{1}$;

O.V. Drugova, PhD, Head of the Laboratory of Electrophysiology and Living Systems Modeling, Institute of Information Technologies, Mathematics, and Mechanics ${ }^{1}$;

V.A. Kostin, PhD, Associate Professor, Department of System Dynamics and Control Theory, Institute of Information Technologies, Mathematics, and Mechanics ${ }^{1}$; Senior Researcher, Department of Plasma Physics²;

I.V. Mukhina, DSc, Professor, Head of the Center for Translational Technologies ${ }^{1}$;

Head of Central Scientific Research Laboratory ${ }^{3}$; Head of the Department of Normal Physiology named after N.Y. Belenkov ${ }^{3}$;

Professor, Department of Neurotechnologies, Institute of Biology and Biomedicine"

G.V. Osipov, DSc, Professor, Head of the Department of Systems Control and Dynamics Theory, Institute of Information Technologies, Mathematics, and Mechanics ${ }^{1}$; Head of the Institute of Supercomputer Technologies ${ }^{1}$

${ }^{1}$ National Research Lobachevsky State University of Nizhny Novgorod, 23 Prospekt Gagarina, Nizhny Novgorod, 603950, Russia;

${ }^{2}$ Federal Research Center Institute of Applied Physics of the Russian Academy of Sciences, 46 Ul'yanova St., Nizhny Novgorod, 603950, Russia;

${ }^{3}$ Privolzhsky Research Medical University, 10/1 Minin and Pozharsky Square, Nizhny Novgorod, 603005, Russia;

The aim of the study was to assess the effect of mechanical right atrium distension of the isolated rat heart on the heart rate and heart rate variability, and the velocity of excitation wave propagation in the left ventricular myocardium using multielectrode mapping with flexible arrays.

Materials and Methods. Experimental studies have been performed on the isolated rat heart in compliance with the Langendorff technique. Electrical heart activity was recorded using a flexible multielectrode array system.

Results. Characteristic electrophysiological parameter changes of the isolated heart with the right atrium distension were detected using multielectrode mapping with flexible arrays. The flexible array design allowed registration of electrical potentials from the left ventricular surface of the actively contracting rat heart perfused according to the Langendorff technique and assessment of interconnection in the work of different parts of the heart: the right atrium in which the sinus node regulating the heart rate is located and the left ventricle. Application of multiple electrodes arranged in a specific way in the array made it possible to analyze spatio-temporal characteristics of electrical activity on the heart surface and to establish both the increase of the sinus node excitation frequency and excitation wave propagation velocity in the left ventricle.

Conclusion. The growth of heart rate variability may suggest the existence of additional mechano-induced processes generating electrical instability in the distended atrium. The effects detected in the left ventricle with the given method may be caused by triggering intracardial regulation mechanisms.

Key words: isolated heart; multielectrode mapping; right atrium distension; heart rate variability; excitation wave propagation in myocardium.

\section{Introduction}

Heart response to mechanical stimuli is controlled by the vegetative nervous system of the body. Electrical signals from mechanoreceptors of the atria, ventricles, and vessels via the vagus nerve fibers are transmitted to the medulla oblongata responsible for heart rhythmogenesis. For example, when ostia venae cavae and the right atrium

Corresponding author: Elena E. Kharkovskaia, e-mail: elharkov@gmail.com 
(RA) are distended, adaptation physiological mechanism of heart rate (HR) acceleration is triggered. It facilitates the removal of the excessive blood volume from the heart, Bainbridge reflex, which is eliminated when the heart is denervated [1]. Heart response to mechanical action may be controlled by its own intracardiac nervous system. In the 70s of the XX century, Kositsky on his experiments on the isolated hearts of the warm-blooded animals showed that mechano-sensitive receptor excitation in atrium distension leads to the changes in the ventricular contraction force [2].

Heart activity optimization under mechanical load may also be realized at the level of cardiac muscle fibers according to the Frank-Starling law [3, 4]. It has been established that apart from the excitationcontraction coupling due to which an electrical signal causes muscle fibers to contract there is also a reverse contraction-excitation coupling. This reverse coupling changes electrical processes in myocardium under the influence of the mechanical stress [5]. The mechanical action can regulate myocardium metabolism influencing the condition of mechanosensitive cell channels $[6,7]$, cytoskeleton proteins, and extracellular matrix [8, 9].

The impact of mechanical action on the heart work is confirmed by observations from the medical practice: cases of sudden death from a blow to the chest in the area of the heart or arrhythmias occurring during catheterization [10, 11]. Mechanical sensitivity is being actively studied at various levels from a cell to the whole organ [12-16] and in different parts of the heart: atria and ventricles [17-19]. Nevertheless, the mechanisms underlying cardiac response to mechanical interventions are left obscure. Knowledge of their nature may open great potentialities for prevention and treatment of cardiac diseases and be the basis for developing novel methods of artificial heart work regulation.

Owing to the development of experimental technologies, it became now possible to investigate in greater detail myocardium properties directly during its active work. For example, it is possible to assess the influence of RA distension on the excitation conductance velocity in ventricles with the help of multielectrode technique for measuring electrical potentials which is presently successfully applied in various modifications for different purposes in research laboratories and medical settings over the world [20-22].

The aim of the study was to assess the effect of right atrium distension on the velocity of excitation propagation in the left ventricle using a mapping technique with flexible multielectrode arrays for signal recording which allows the understanding of intracardial mechanisms of isolated heart regulation: electrical wave processes in the heart, heart rate and heart rate variability in norm and pathology.

\section{Materials and Methods}

Langendorff heart perfusion. The experimental work was carried out in compliance with the orders No.1179 MH USSR of 11.10.1983 and No.267 MH RF of 19.06.2003, experiments were conducted in conformity with the Guide for the Care and Use of Laboratory Animals (National Research Council, 2011) met the requirements of the European Convention for the Protection of Vertebrate Animals used for Experimental and Other Scientific Purposes (Strasbourg, 2006).

White outbred rats weighing 200-250 g were injected intraperitoneally with heparin (500 ME) and an anesthetic agent (Zoletil 100, $35 \mathrm{mg} / \mathrm{kg}$ ). Thoracotomically removed hearts were subjected to gravitational retrograde Langendorff perfusion. Krebs-Henseleit solution (in $\mathrm{mmol} / \mathrm{L})$ was used for perfusion: $118 \mathrm{NaCl} ; 4.7 \mathrm{KCl}$; $2 \mathrm{CaCl}_{2} ; 1.2 \quad \mathrm{MgSO}_{4} ; 1.2 \quad \mathrm{KH}_{2} \mathrm{PO}_{4} ; 20 \quad \mathrm{NaHCO}_{3}$; 10 glucose; $\mathrm{pH} 7.3-7.4$ at $37^{\circ} \mathrm{C}$ under $80 \mathrm{~mm} \mathrm{H}_{2} \mathrm{O}$ pressure and saturation with a gas mixture containing $95 \% \mathrm{O}_{2}$ and $5 \% \mathrm{CO}_{2}$ (Figure 1 (a)). RA distension was obtained by filling its chamber with a high-molecular polyethylene (Figure 1 (b)).

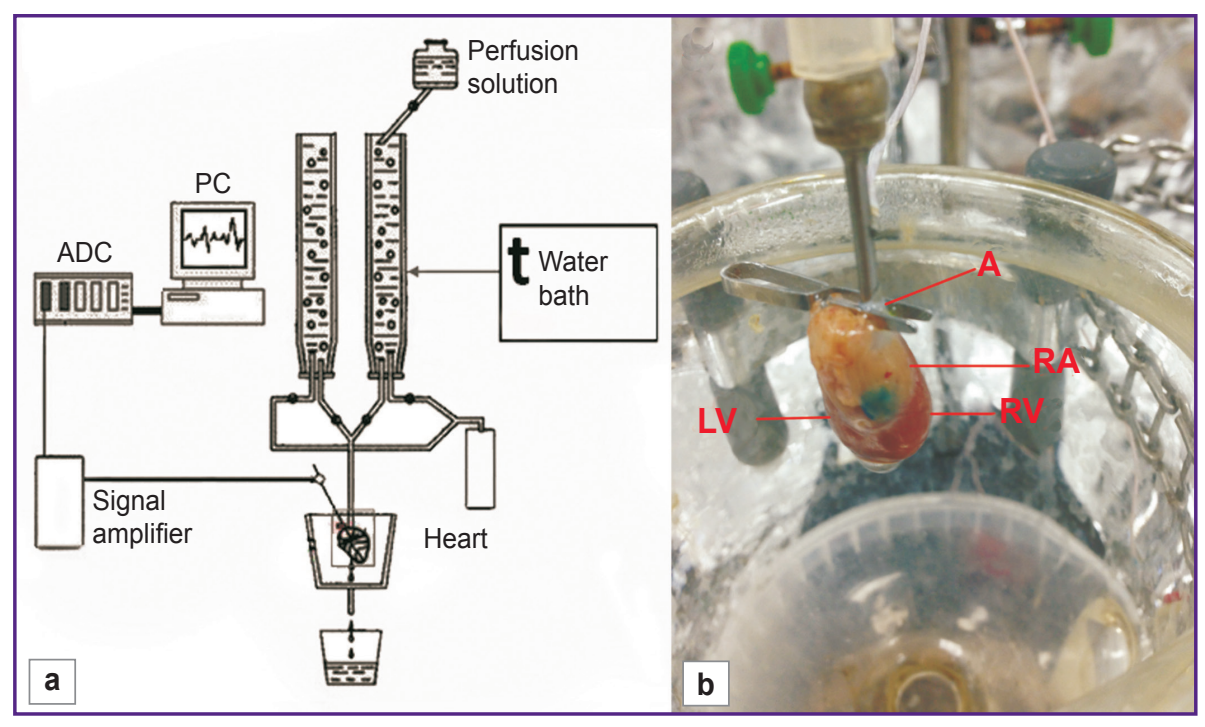

Figure 1. Perfusion of the isolated rat heart according to Langendorff technique:

(a) the diagram of perfusion system: ADC - analog-to-digital converter; PC - personal computer; (b) a rat heart with a blue implant placed in the right atrium (RA); A - aorta fixed to the cannula with a clamp; LV - left ventricle; RV - right ventricle 
Method of recording electrical cardiac activity. Electrical cardiac activity was recorded with a system of flexible multielectrode arrays (MEAFlex72; Multi Channel Systems MCS $\mathrm{GmbH}$, Germany). The array package (Figure 2 (a)) is made of a flexible polyimide and houses 72 electrodes: 64 recording, 4 refractory, and 4 grounding electrodes assembled in a structured array on the contact pad area (Figure 2 (b)) Electrical signals from the left ventricular (LV) surface (Figure 2 (c)) via the array electrodes arrived at the system consisting of amplifiers, filters, and an analog-digital converter (Multi Channel Systems MCS $\mathrm{GmbH}$, Germany) for recording, visualization and saving of digital files for further processing (Figure 2 (d)).

The experiment protocol. The investigation included two stages: the first stage was performed with the heart contracting under normal conditions, the second under mechanical RA distension. The parameters of the heart work obtained over the first $5 \mathrm{~min}$ of the second stage were compared to the parameters of the last minute of the first stage. The results of the investigations in the experimental group (mechanical RA distension) were compared to the controls (perfusion under normal conditions). Ten experiments were carried out in each group.

The analysis of the heart work parameters. The electrode system enables the analysis of the cardiac rhythm in order to assess such characteristics as heart rate, variability of $R-R$ intervals, which is reflected by the coefficient of variation $(\mathrm{CV})$ defined as $\mathrm{CV}(\%)=\mathrm{SD} / \mathrm{M}$, where $\mathrm{SD}$ is standard deviation and $\mathrm{M}-$ a mean value of $\mathrm{R}-\mathrm{R}$ intervals [23].

Since ECG was not used in the given experiment, the terms "R-wave" and "R-R interval" are used conventionally. The positions of R-waves corresponded to the time of signal entry to the array electrodes. These positions were determined on the basis of semi-interactive analysis of the taken time-dependent voltages. A threshold filter with the parameters set in the manual mode for an individual experimental heart and array electrode was the basis of this analysis. This filter was used to the time potential derivative on one of the array electrodes and the moments of maximums and minimums occurrences conventionally marked as R-waves were determined in the obtained dependence. Time periods between adjacent $R$-waves defined in this way were assumed to be $R-R$ intervals the sequence of which was then used to analyze the heart rate and heart rate variability.

A great number of recording electrodes in the array provide the possibility to analyze the velocity of excitation wave propagation in the LV myocardium with the help of Cardio2D software application (Multi Channel Systems MCS GmbH, Germany). The myocardium architectonics does not allow the recording of the wide excitation wave

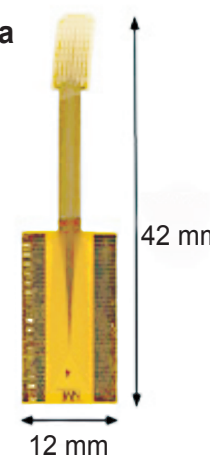

b

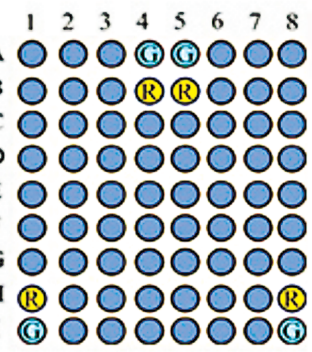

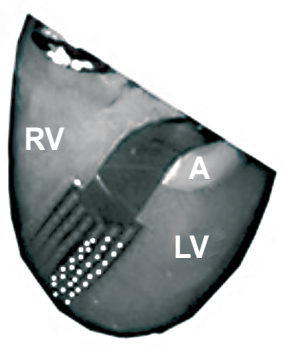

Figure 2. Multielectrode recording of cardiac electrical activity: (a) multielectrode flexible array; (b) electrode array on the recording plate: recording electrodes are colored dark blue, reference electrodes (R) - yellow; grounding electrodes (G) - blue; (c) flexible array located on the left ventricular (LV) surface on the border with the right ventricle (RV) below the auricle $(A)$ of the isolated rat heart; d) visualization of the recorded electrograms

front on the heart surface [24]. That is why the value of excitation time delay between the electrodes in the sample group (of 9 electrodes minimum) gives an idea of the excitation propagation velocity in the myocardium.

Statistical data analysis. The obtained results were processed by variation statistics methods using Microsoft Office Excel 2003 application in the operating system Microsoft Windows 7. All general recommendations for medical and biological investigations were observed.

Shapiro-Wilk test was used to test the conformity of empirical data distribution to normal distribution. The data following the normal law of distribution were presented as mean $\mathrm{M}$ and standard error of the mean $\mathrm{m}$ (SEM). If the test showed that the samples did not correspond to the normal distribution law, the data were presented as range charts including central trends (median Me), the $25^{\text {th }}$, and $75^{\text {th }}$ percentiles, minimal and maximal values.

\section{Results}

Heart rate variability. Heart response to mechanical distension of the RA cavity was expressed as the increase of the heart rate (HR) and heart rate variability. The electrograms (Figure 3 ) reflect the increase of $R-R$ 


\section{EXPERIMENTAL INVESTIGATIONS}

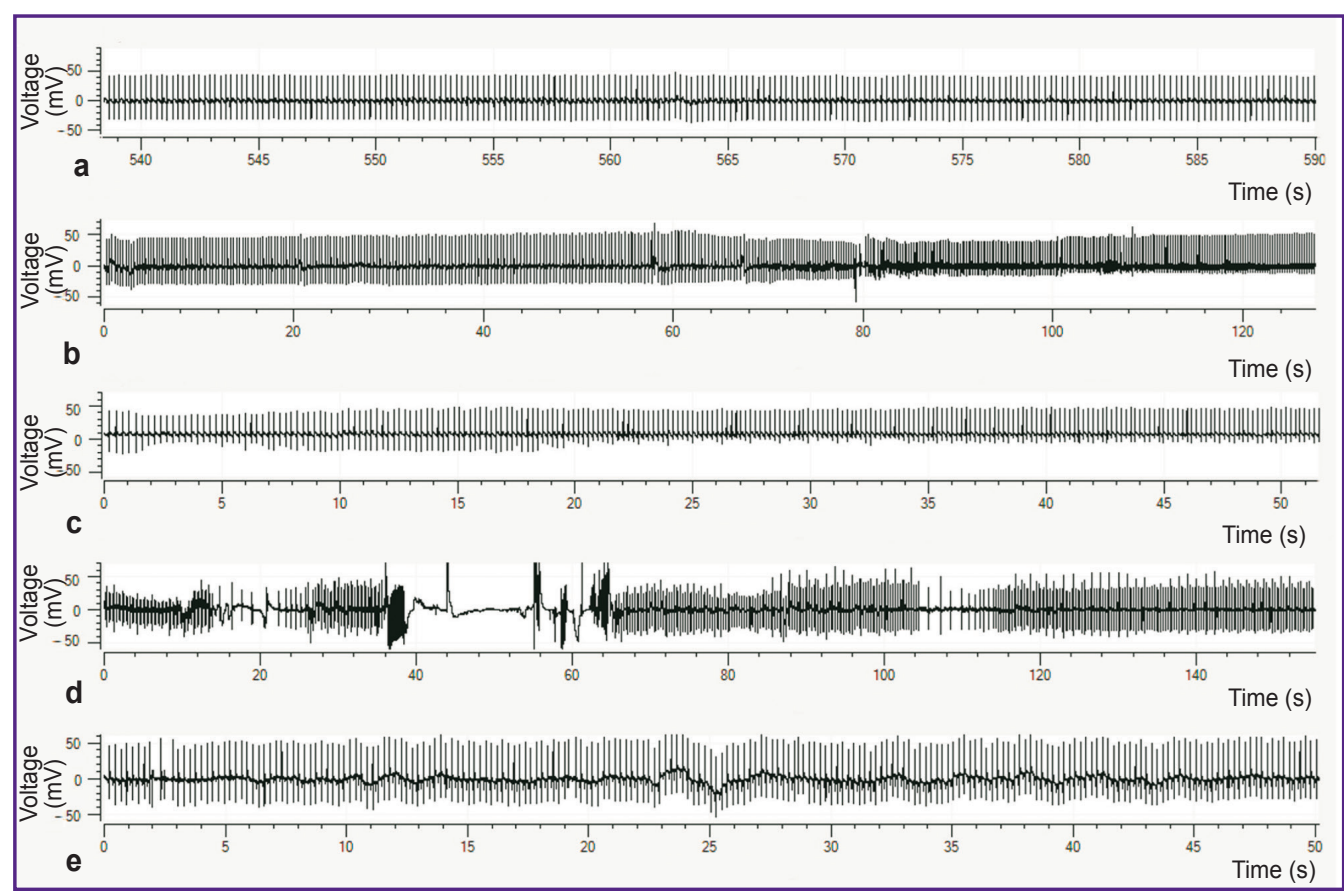

Figure 3. Electrograms of five isolated hearts:

(a) before mechanical distension of the right atrium; (b)-(e) after mechanical distension of the right atrium for four different isolated hearts

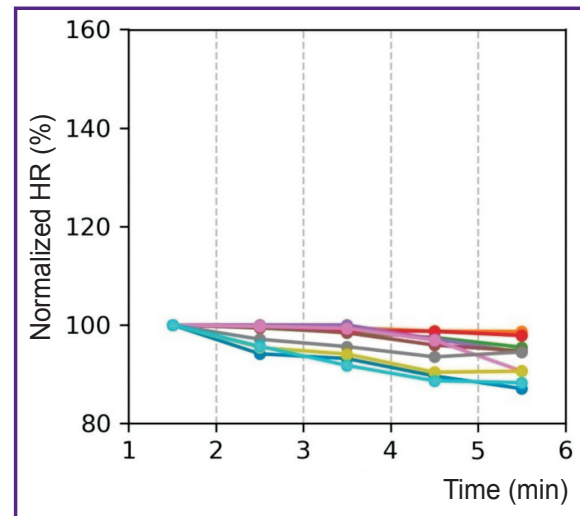

a
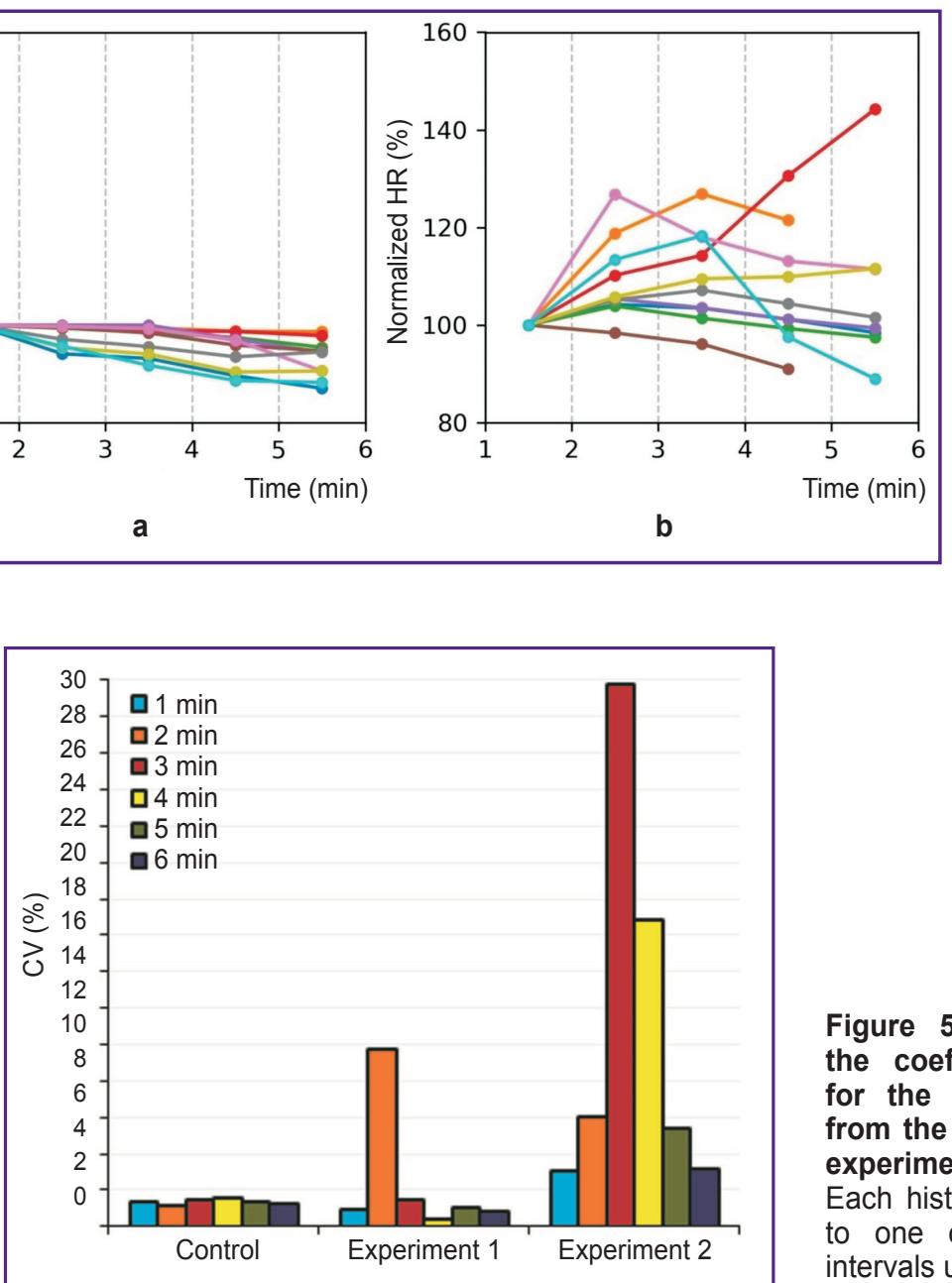

Figure 4. Time dependence of the heart rate normalized to the value of the $2^{\mathrm{d}}$ minute of the experiment:

(a) in 10 rat hearts from the control group; (b) in 10 rat hearts from the experimental group where mechanical distension of the right atrium was done immediately before the beginning of the $2^{\mathrm{d}}$ minute
Figure 5. Time dependences of the coefficient of variability CV for the isolated rat hearts: one from the control and two from the experimental group

Each histogram column corresponds to one of the successive minute intervals used for statistical analysis 
intervals variability from the $1^{\text {st }}$ minute of mechanical RA distension which is manifested with different intensity and duration in various hearts.

Charts in Figure 4 show that, in contrast to the control experiments, under the normal perfusion condition HR (Figure 4 (a)) increases after mechanical RA distension (Figure 4 (b)). During the $1^{\text {st }}$ minute, the $\mathrm{HR}$ value was registered in the experimental group under normal conditions and made on average $222.6 \pm 22.8$ per minute. After the $1^{\text {st }}$ minute, the cardiac RA cavity was distended, and from the $2^{\mathrm{d}}$ minute a considerable dispersion of the HR values was observed. Figure 4 shows normalized HR values determined for the 5 successive minute intervals and referred to the value in the $2^{d}$ minute (the $1^{\text {st }}$ minute after distension) for a concrete heart.

Figure 5 illustrates the alteration of coefficient of variability $\mathrm{CV}$ associated with mechanical RA distension. Dispersion of R-R interval duration values is (b) hearts

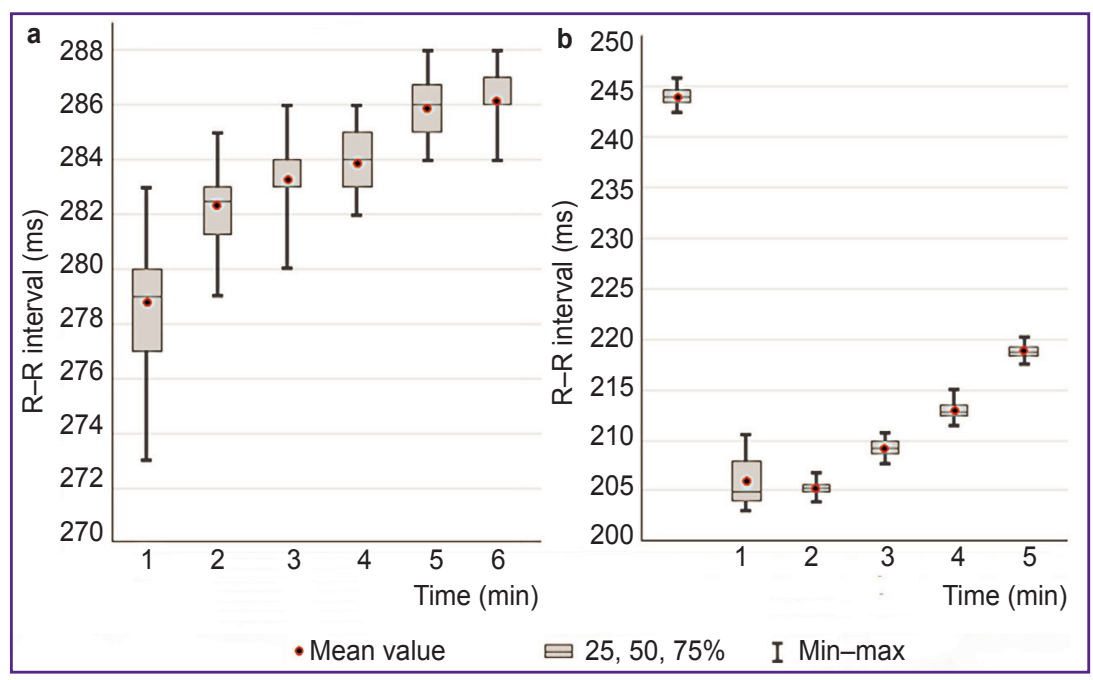

Figure 6. Diagram of R-R interval range for the control (a) and experimental

Mean and median values, the $25^{\text {th }}$ and $75^{\text {th }}$ percentiles, minimal and maximal values are represented. These values were obtained by statistical analysis of 50 successive R-R intervals taken at the beginning of the 6 successive time intervals of 1-minute duration

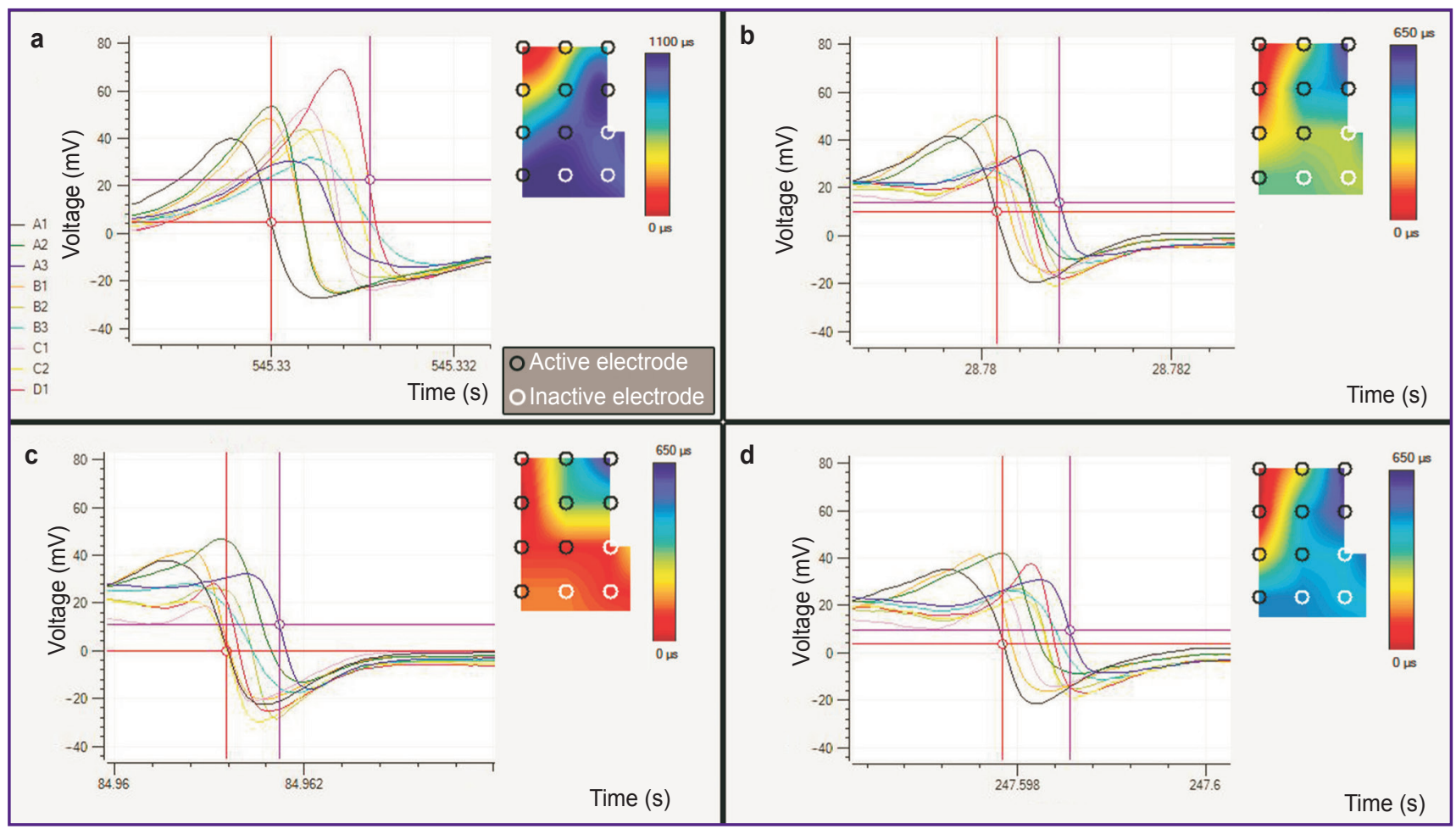

Figure 7. Fragments of electrograms taken from different electrodes illustrating the alteration of time delay between $R$-waves in various points of the left ventricular myocardium

Red and violet lines show the time of excitation recorded on the first and last electrodes, respectively, of all (A1-D1) selected electrodes in norm (i.e. before distension) (a) and after mechanical distension near the selected time moments during the $1^{\text {st }}$ (b), $2^{\mathrm{d}}(\mathrm{c})$, and $5^{\text {th }}(\mathrm{d})$ minutes; on the activation maps to the right from the plots, the thermal map shows software interpolated spatial distribution of the potential near the selected electrodes and illustrates the form of the excitation wave front and the number of active electrodes at a specified moment of time 
under the normal conditions, after the $1^{\text {st }}$ minute the RA cavity was distended.

Velocity of excitation wave propagation in the myocardium. After RA distension (Figure 7 (b)-(d)), time delay of excitation record between the array electrodes in the LV myocardium decreased on average by $1.9 \pm 0.3$ times compared to the period before the distension. In the control group, no changes in the length of time delay were observed during $5 \mathrm{~min}$.

\section{Discussion}

The RA distension of an isolated rat heart has been found by our study to result in the HR increase. Previously, the same results were obtained in similar studies on isolated hearts of the worm-blooded animals $[25,26]$ and on the isolated sinus node under distended conditions [27]. A positive chronotropic reaction implies participation of a special intracardiac reflex independent of the vagus nerve similar to Bainbridge reflex.

HR growth occurs during the $1^{\text {st }}$ minute after distension and is accompanied by ventricular arrhythmias, which is likely to be connected with a heart adaptative response. Model investigations previously conducted on the self-oscillating cardiac cells [17] showed their capability of increasing the frequency of impulsation after distension, and the reaction like this may be explained by the activation of nonspecific mechanosensitive channels and alteration of the channel membrane currents generating an action potential. Based on this, it may be supposed that HR growth observed in our work is connected with direct activation of the sinoatrial node cells with mechanical action. However, in contrast to the momentary rate increase observed in the cardiomyocyte preparations or cardiac muscle sections, instant response in the whole organ does not occur.

It is noteworthy that the response to RA distension was evaluated by the electrophysiological parameters of the working myocardium. And under retrograde perfusion, insufficient intraventricular pressure and volume implies high velocity and low force of contraction. In such case, HR increase must not induce excitation and contractility disorders. Excitation frequency increase was shown to be accompanied with the increase of excitation wave propagation velocity in the LV. However, attention should be paid to the elevation of the heart rate variability in presence of distension which is especially high at the initial stages of distension. If the appearance of the positive chronotropic reaction in response to the distension is considered as evidence of intracardial reflex previously described in the works of Kositsky [2], one cannot but take into consideration the inherent positive inotropic effect which suggests $\mathrm{Ca}^{2+}$-current amplification in the action potential plateau phase. The excess of $\mathrm{Ca}^{2+}$ ions may result in electrical instability in the cardiac ventricles and arrhythmia development.

\section{Conclusion}

The method of multielectrode mapping with flexible arrays enables detection of characteristic changes in electrophysiological parameters of the isolated heart under RA distension. The flexible array design allowed recording of electrical potentials from the left ventricular surface of the actively contracting rat heart perfused according to the Langendorff technique.

Application of this matrix allowed us to establish interconnection in the work of different parts of the heart: the right atrium in which the sinus node regulating the heart rate is located and the left ventricle. Application of multiple electrodes arranged in a particular way in the array made it possible to analyze spatio-temporal characteristics of electrical activity on the heart surface and to establish both the increase of the sinus node excitation frequency and excitation wave propagation velocity in the left ventricle. The growth of heart rate variability may suggest the existence of additional mechano-induced processes of generating electrical instability in the distended atrium. The effects detected in the left ventricle with the given method are likely to be caused by triggering intracardial regulation mechanisms.

Study funding. The work was supported by the Russian Foundation for Basic Research within the project 17-02-00467 "Investigation of the collective dynamics of the mixed media consisting of the elements possessing qualitatively different behavior and having a complicated topology of links".

Conflicts of interest. The authors have no conflicts of interest.

\section{References}

1. Bainbridge F.A. The influence of venous filling upon the rate of the heart. J Physiol 1915; 50(2): 65-84, https://doi. org/10.1113/jphysiol.1915.sp001736.

2. Kositsky G.I. Afferentnye sistemy serdtsa [The afferent systems of the heart]. Moscow: Meditsina; 1975; 207 p.

3. Frank O. Zur Dynamik des Herzmuskels. Z Biol 1895; 32: 370-447.

4. Patterson S.W., Starling E.H. On the mechanical factors which determine the output of the ventricles. Physiol 1914; 48(5): 357-379.

5. Kamkin A.G., Yarygin V.N., Kiseleva I.S. Mekhanoelekgricheskaya obratnaya svyaz' v serdtse [Mechanoelectric feedback in the heart]. Moscow: Natyurmort; 2003; 352 p.

6. Teng J., Loukin S., Kung C. Mechanosensitive ion channels in cardiovascular physiology. Exp Clin Cardiol 2014; 20(10): 6550-6560.

7. Inoue R., Jian Z., Kawarabayashi Y. Mechanosensitive TRP channels in cardiovascular pathophysiology. Pharmacol Ther 2009; 123(3): 371-385, https://doi.org/10.1016/j. pharmthera.2009.05.009.

8. McCain M.L., Parker K.K. Mechanotransduction: the role of mechanical stress, myocyte shape, and cytoskeletal architecture on cardiac function. Pflugers Arch 2011; 462(1): 89-104, https://doi.org/10.1007/s00424-011-0951-4. 
9. Young J.L., Kretchmer K., Ondeck M.G., Zambon A.C., Engler A.J. Mechanosensitive kinases regulate stiffnessinduced cardiomyocyte maturation. Sci Rep 2014; 4(1): 6425, https://doi.org/10.1038/srep06425.

10. Schlomka G. Commotio cordis und ihre Folgen. (Die Einwirkung stumpfer Brustwandtraumen auf das Herz). In: Czerny A., Kraus F., Müller F., v. Pfaundler M., Schittenhelm A. (editors). Ergebnisse der Inneren Medizin und Kinderheilkunde. Springer, Berlin, Heidelberg; 1934; p. 1-91, https://doi. org/10.1007/978-3-642-90672-5_1.

11. Michel J., Johnson A.D., Bridges W.C. Arrhythmias during intracardiac catheterization. Circulation 1950; 2(2): 240 250, https://doi.org/10.1161/01.cir.2.2.240.

12. Brohawn S.G., Su Z., MacKinnon R. Mechanosensitivity is mediated directly by the lipid membrane in TRAAK and TREK1 K+ channels. Proc Natl Acad Sci USA 2014; 111(9): 3614-3619, https://doi.org/10.1073/pnas.1320768111.

13. Thompson S.A., Copeland C.R., Reich D.H., Tung L. Mechanical coupling between myofibroblasts and cardiomyocytes slows electrical conduction in fibrotic cell monolayers. Circulation 2011; 123(19): 2083-2093, https://doi. org/10.1161/circulationaha.110.015057.

14. Vandebrouck C., Martin D., Colson-Van Schoor M., Debaix H., Gailly P. Involvement of TRPC in the abnormal calcium influx observed in dystrophic $(\mathrm{mdx})$ mouse skeletal muscle fibers. J Cell Biol 2002; 158(6): 1089-1096, https://doi. org/10.1083/jcb.200203091.

15. Wang K., Terrar D., Gavaghan D.J., Mu-u-min R., Kohl P., Bollensdorff C. Living cardiac tissue slices: an organotypic pseudo two-dimensional model for cardiac biophysics research. Prog Biophys Mol Biol 2014; 115 (2-3): 314-327, https://doi.org/10.1016/j.pbiomolbio.2014.08.006.

16. Filgueiras-Rama D., Martins R.P., Ennis S.R., Mironov S., Jiang J., Yamazaki M., Kalifa J., Jalife J., Berenfeld $\mathrm{O}$. High-resolution endocardial and epicardial optical mapping in a sheep model of stretch-induced atrial fibrillation. J Vis Exp 2011; 53: 3103, https://doi.org/10.3791/3103.

17. Nazir S.A., Lab M.J. Mechanoelectric feedback in the atrium of the isolated guinea-pig heart. Cardiovasc Res 1996; 32(1): 112-119, https://doi.org/10.1016/s0008-6363(96)00077-6.

18. Franz M.R. Mechano-electrical feedback in ventricular myocardium. Cardiovasc Res 1996; 32(1): 15-24, https://doi. org/10.1016/s0008-6363(96)00074-0.

19. Quinn T.A., Kohl P. Mechano-sensitivity of cardiac pacemaker function: pathophysiological relevance, experimental implications, and conceptual integration with other mechanisms of rhythmicity. Prog Biophys Mol Biol 2012; 110 (23): 257-268, https://doi.org/10.1016/j.pbiomolbio.2012.08.008.

20. Bokeriya L.A., Filatov A.G. Mapping of arrhythmias. Annaly aritmologii 2012; 9(1): 5-13.

21. Vigmond E.J., Efimov I.R., Rentschler S.L., Coronel R., Boukens B.J. Fractionated electrograms with ST-segment elevation recorded from the human right ventricular outflow tract. HeartRhythm Case Rep 2017; 3(11): 546-550, https:// doi.org/10.1016/j.hrcr.2017.08.010.

22. Linnenbank A.C., de Bakker J.M.T., Coronel R. How to measure propagation velocity in cardiac tissue: a simulation study. Front Physiol 2014; 5: 267, https://doi.org/10.3389/ fphys.2014.00267.

23. Baevskiy R.M., Ivanov G.G., Chireykin L.V., Gavrilushkin A.P., Dovgalevskiy P.Ya., Kukushkin Yu.A., Mironova T.F., Prilutskiy D.A., Semenov A.V., Fedorov V.F., Fleyshman A.N., Medvedev M.M. Analysis of heart rate variability using different electrocardiographic systems: methodical recommendations. Vestnik aritmologii 2001; 24: 65-86.

24. Hooks D.A., Tomlinson K.A., Marsden S.G., LeGrice I.J., Smaill B.H., Pullan A.J., Hunter P.J. Cardiac microstructure: implications for electrical propagation and defibrillation in the heart. Circ Res 2002; 91(4): 331-338, https://doi.org/10.1161/01.res.0000031957.70034.89.

25. Tiitso M. Chronotrope Wirkungen der Spannungsänderungen des rechten Vorhofes. Pflugers Arch Gesamte Physiol Menschen Tiere 1937; 238(1): 738-748, https://doi.org/10.1007/bf01767681.

26. Blinks J.R. Positive chronotropic effect of increasing right atrial pressure in the isolated mammalian heart. $\mathrm{Am}$ J Physiol 1956; 186(2): 299-303, https://doi.org/10.1152/ ajplegacy.1956.186.2.299.

27. Deck K.A. Effects of stretch on the spontaneously beating, isolated sinus node. Pflugers Arch Gesamte Physiol Menschen Tiere 1964; 280: 120-130. 